\title{
Crustal permeability
}

\author{
Steve Ingebritsen $^{1} \cdot$ Tom Gleeson ${ }^{2}$
}

Received: 16 May 2017 / Accepted: 15 August 2017 / Published online: 2 September 2017

(C) The Author(s) 2017. This article is an open access publication

\begin{abstract}
Permeability is the dominant parameter in most hydrogeologic studies. There is abundant evidence for dynamic variations in permeability in time as well as space, and throughout the crust. Whether this dynamic behavior should be included in quantitative models depends on the problem at hand.
\end{abstract}

Keywords Permeability · Brittle-ductile transition .

Crystalline rocks $\cdot$ Fault zones

\section{Introduction}

A physicist colleague once remarked that the entire field of groundwater hydrology seems to consist of pursuit of a single parameter - permeability $(k)$. He further noted that permeability is an awkward parameter, defined indirectly based on Darcy's law, and is scale dependent and difficult to measure. Most hydrogeologists would concede that these claims contain an element of truth, but nearly all of us agree that characterization of permeability is essential to quantify the flow of fluids through the Earth's crust, which impacts crustal rheology and deformation as well as the transfer of matter and energy.

There is a longstanding gulf between the hydrogeologic perspective of permeability as an essentially static material property that exerts control on fluid flow and the perspective of economic geologists, crustal petrologists, and others who recognize permeability as a dynamic parameter that changes in response to tectonism, fluid production, and geochemical reactions.

Steve Ingebritsen

seingebr@usgs.gov

US Geological Survey, Menlo Park, CA, USA

2 University of Victoria, Victoria, BC, Canada
Consider for instance the credibility gap between a geologist who, based on careful study of outcrops, recognizes the signature of many cycles of permeability creation and decay (e.g. Cann et al. 2016; Micklethwaite et al. 2016) and a hydrogeologist who might tend to simulate the same flow system using constant hydraulic properties. Issues associated with hydraulic fracturing, enhanced geothermal systems, and geologic carbon sequestration have begun to promote a constructive dialog between the 'static' and 'dynamic' views of permeability, helping to bridge this historical dichotomy. Additionally, although the very term 'intrinsic permeability' seems to imply an immutable property, there is abundant evidence that permeability varies in time as well as space. Temporal variability in permeability is particularly pronounced in environments characterized by high strain rates and/or strong chemical and thermal disequilibrium.

\section{The journey from deep crust to the uppermost crust}

\section{Below the brittle-ductile transition}

Most of the Earth's crust lies below the brittle-ductile transition (BDT), where hydrogeologists rarely venture. The continental crust is typically $25-70 \mathrm{~km}$ thick, the geothermal gradient is roughly $25^{\circ} \mathrm{C} / \mathrm{km}$, and the BDT occurs at a temperature of roughly $350-400{ }^{\circ} \mathrm{C}$ (depending on rock type and strain rate), thus at a typical crustal depth of only $10-15 \mathrm{~km}$ (Fig. 1). In areas with adequate seismic data such as southern California (USA) (Nazareth and Hauksson 2004) and Japan (Tanaka and Ishikawa 2005), the BDT can be mapped as the base of the seismogenic crust.

Available data continue to support a general distinction between the hydrodynamics of the brittle upper crust, where topography and magmatic heat sources dominate patterns of flow and externally derived (meteoric) fluids are common, 


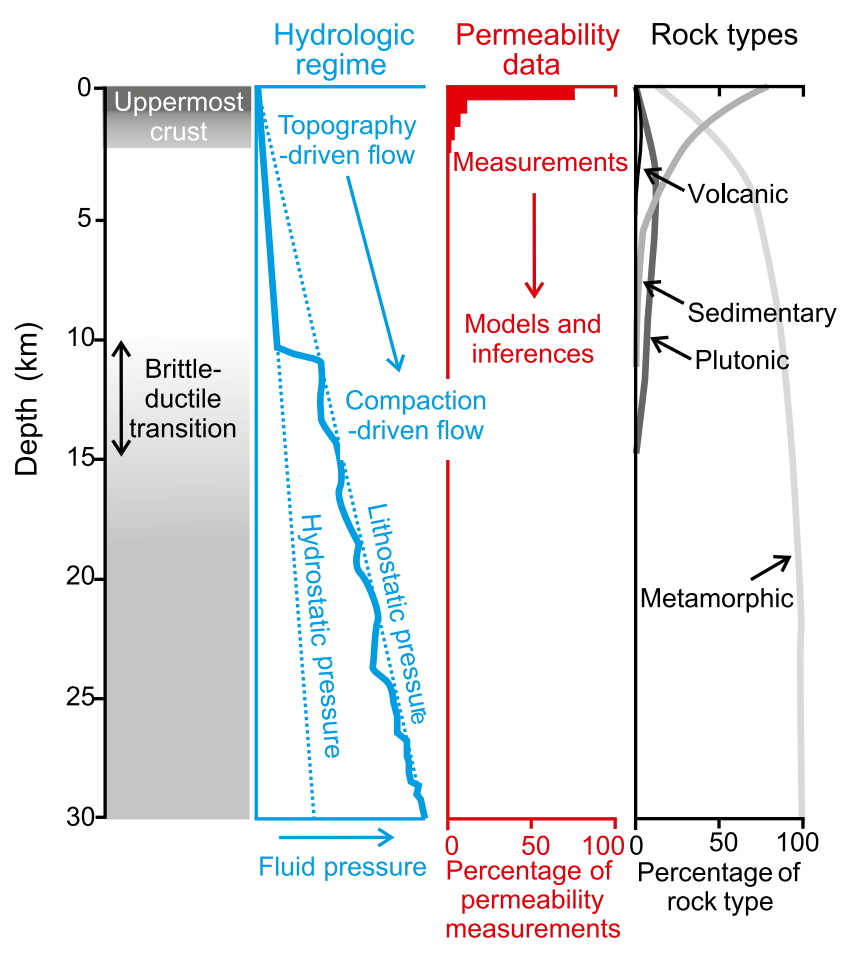

Fig. 1 Hydrologic regimes, permeability data, and rock types from 0 to $30 \mathrm{~km}$ depth in the continental crust (modified from Wilkinson et al. 2009; Connolly and Podladchikov 2016; and Ranjram et al. 2016)

and those of the ductile lower crust, dominated by (de)volatilization reactions and internally derived fluids (Ingebritsen and Manning 1999). The apparent absence of a permeability discontinuity or barrier at the transition implies that fluids produced in the middle and lower crust during metamorphism can be transmitted to the upper crust.

For many crustal-scale hydrogeologic problems, the BDT may reasonably be considered the lower boundary of the domain of interest. However, the underlying ductile regime can be an important fluid source to the brittle regime, affecting the cycling of certain elements and perhaps even balancing the global water cycle over geologic time. Consider for instance that the time-integrated metamorphic fluid flux from a Himalayan-scale orogeny represents a water volume $10 \times$ greater than the total amount in Earth's rivers and lakes (Jay Ague, Yale University, unpublished data, 2012).

Yardley (2016) posits a fundamental difference between regions where the continental crust is being thickened and/or heated (prograde metamorphism, less common) and where the crust is stable and/or cooling (retrograde metamorphism, more common). In regions of prograde metamorphism, porosity waves may expel fluids from ductile rocks below the BDT. Connolly and Podladchikov (2016) present a general, analytical steady-state solution to predict the dynamic variations in fluid pressure and permeability necessary to accommodate fluid production. Weis (2016) considers magmatichydrothermal systems, where igneous intrusion causes the BDT to be unusually shallow, and where transport of heat and matter spanning the BDT is essential to create economically useful metal deposits. Weis adopts a dynamicpermeability model in which permeability generally follows a power-law depth-dependent relation but can increase with pressure above the BDT and both decrease with temperature and increase with pressure below the BDT. This $k(z, T, P)$ model reflects current understanding of the mechanics of rock failure. Recent empirical data appear to support the persistence of permeability (Watanabe et al. 2017), and thus potentially exploitable geothermal resources, below the BDT.

\section{Between the brittle-ductile transition and the 'uppermost crust'}

The depth range between the BDT and roughly $2-\mathrm{km}$ depth is still largely terra incognito from a hydrogeologic perspective, but fundamentally important from the standpoint of energy resources (oil, gas, geothermal), geologic carbon sequestration, certain options for nuclear waste disposal, induced seismicity (and tectonism in general), ore deposits, global biogeochemical cycles, and life in the deep biosphere.

As is the case below the BDT, rocks in this depth range are most likely metamorphic (Fig. 1; Wilkinson et al. 2009). Metamorphic rocks constitute about $90 \%$ of the continental crust by volume, though only $11 \%$ of surface exposures. In contrast, sedimentary rocks, the focus of most hydrogeologic research, constitute only a few percent of crustal volume, despite $\sim 73 \%$ of surface exposures.

In considering permeability (and hydrogeologic conditions in general) between the BDT and the uppermost crust, it is of interest to note that enhanced geothermal systems, geologic carbon sequestration (Lucier and Zoback 2008), and deep injection of waste fluid (Hsieh and Bredehoeft 1981; Weingarten et al. 2015) all entail similar stimuli, namely fluid-injection rates on the order of $10 \mathrm{~s}$ of $\mathrm{kg} / \mathrm{s}$, as do simulations of ore-forming systems (e.g. Weis 2016). In North America, fluid-injection practices have caused a recent and dramatic increase in $\mathrm{M}_{\mathrm{w}}>3$ seismic events (e.g. Ellsworth 2013). An unintended consequence of this ongoing injection experiment is the opportunity to explore and assess dynamic crustal permeability to depths of perhaps $10 \mathrm{~km}$.

\section{The uppermost crust (0-2 km depth)}

Direct permeability measurements are abundant only in the uppermost crust, roughly $0-2 \mathrm{~km}$ depth, and even here the availability of data diminishes greatly below about $0.5 \mathrm{~km}$ depth (Fig. 1; Ranjram et al. 2016; Achtziger-Zupancic et al. 2017). The permeability structure of the uppermost crust is highly heterogeneous and, whereas a wide variety of $k-z$ relations have been suggested, it is risky to extrapolate crustalscale $k-z$ relations to the uppermost crust, or perhaps even to define such relations (e.g. Ranjram et al. 2016; Burns et al. 2016). The permeability of clastic sediments in the cool 
shallow crust is often well-predicted as a function of mechanical compaction and consequent porosity-permeability relations (e.g. Luijendijk and Gleeson 2016; Daigle and Screaton 2016). However, this predictability diminishes at depths where diagenetic processes become important; similarly, hydrothermal alteration of volcanic rocks tends to cause significant reduction of permeability at temperatures in excess of approximately $40-50{ }^{\circ} \mathrm{C}$ (Burns et al. 2016).

\section{Static or dynamic permeability?}

Temporal changes in permeability can be gradual or abrupt. Streamflow responses to earthquakes demonstrate that dynamic stresses can instantaneously change permeability on a regional scale (e.g. Rojstaczer et al. 1995); large (1 mm) fractures can be sealed by silica precipitation within 10 years (Lowell et al. 1993); and calcite dissolution in coastal carbonate aquifers causes significant changes in porosity and permeability over timescales of $10^{4}-10^{5}$ years (Sanford and Konikow 1989). At the other end of the spectrum, the reduction of pore volume during sediment burial modifies permeability very slowly. For example, shale permeabilities from the US Gulf Coast vary from about $10^{-18} \mathrm{~m}^{2}$ near the surface to about $10^{-20} \mathrm{~m}^{2}$ at $5 \mathrm{~km}$ depth (Neglia 1979), and the natural subsidence rate is $0.1-10 \mathrm{~mm}^{-1}$ year $^{-1}$ (Sharp and Domenico 1976), so one can infer that it takes perhaps $10^{7}$ years for the permeability of a subsiding package of shale to decrease by a factor of 10. Even in the uppermost crust, crustal-scale permeability is a dynamically self-adjusting property, reflecting a competition between permeability destruction by processes such as compaction and permeability creation by processes such as fluid sourcing (e.g. Connolly and Podladchikov 2016; Okada et al. 2016; Miller 2016; Taron et al. 2016; Weis 2016) and tectonically driven fracturing and faulting.

Nonetheless, permeability can reasonably be treated as a static parameter for a wide range of applications in the uppermost crust - for example, for typical low-temperature hydrogeologic investigations with timescales of days to decades, permeability may be considered static in the absence of seismicity. Similarly, if it takes perhaps $10^{7}$ years for the permeability of a subsiding package of shale to decrease by a factor of 10 , permeability in sedimentary basins may be considered static for investigations on much shorter timescales. Whether the dynamic variation of permeability is important to include in analyses depends upon how quickly, and how much, permeability is changing relative to the requirements of the problem at hand.

Recent research on enhanced geothermal reservoirs (Preisig et al. 2016; Miller 2016; Taron et al. 2016), ore-forming systems (Micklethwaite et al. 2016; Weis 2016), and the hydrologic effects of earthquakes (e.g. Okada et al. 2016) yields broadly consistent results regarding permeability enhancement by dynamic stresses. Shear dislocation caused by tectonic forcing or fluid injection can increase near- to intermediate-field permeability by factors of 100 to 1000 . Dynamic stresses (shaking) in the intermediate- to far-field corresponding to seismic energy densities $>0.01 \mathrm{~J} / \mathrm{m}^{3}$ also increase permeability, albeit often by $<<10$ and at most by a factor of approximately 20 (e.g. Wang and Manga 2010; Manga et al. 2012). These permeability increases are transient, tending to return to preseismic values over timescales on the order of months to decades (e.g. Elkhoury et al. 2006; Kitagawa et al. 2007). There is reasonable agreement between the magnitude of near- to intermediate-field permeability increases $\left(10^{2}-10^{3}\right.$ fold) directly measured at enhanced geothermal sites (e.g. Haring et al. 2008), inferred from field evidence (e.g. Saffer 2016; Howald et al. 2016), invoked in simulations of transient hydrothermal circulation (e.g. Howald et al. 2016; Taron et al. 2016; Weis 2016), and inferred from seismic and metamorphic data (Ingebritsen and Manning 2010).

\section{New resources for crustal permeability data}

Most of the foregoing material is discussed in much greater detail in a recent book titled Crustal Permeability that draws on the work of 123 contributors (Gleeson and Ingebritsen 2016). Additional resources have emerged in this era of exploding information technology and accessibility. Fan et al. (2016) outline a vision for the "DigitalCrust": a community-governed, fourdimensional data system emphasizing permeability and porosity. The Crustal Permeability data portal (University of Victoria 2017) is a complementary effort intended to unearth and share permeability data. In contrast to DigitalCrust, the Crustal Permeability data portal will not host data, and data do not have to be spatially located. Data requirements are simply that the data be: peer-reviewed (published in a peer-reviewed journal, book or report); include permeability or other related fluid-flow and transport parameters; and be hosted and publicly available on an online data repository such as figshare or institutional webpages such as those of the US Geological Survey. These new resources should be useful contributions to the understanding of fluid flow in our complex, heterogeneous, fascinating planet.

Open Access This article is distributed under the terms of the Creative Commons Attribution 4.0 International License (http:// creativecommons.org/licenses/by/4.0/), which permits unrestricted use, distribution, and reproduction in any medium, provided you give appropriate credit to the original author(s) and the source, provide a link to the Creative Commons license, and indicate if changes were made.

\section{References}

Achtziger-Zupančič P, Loew S, Mariéthoz G (2017) A new global data base to improve predictions of permeability distribution in crystalline rocks at site scale. J Geophys Res 122(5):3513-3539. https:// doi.org/10.1002/2017JB014106 
Burns ER, Williams CF, Ingebritsen SE, Voss CI, Spane FA, DeAngelo J (2016) Understanding heat and groundwater flow through continental flood basalt provinces: insights gained from alternative models of permeability / depth relationships for the Colorado Plateau, United States. In: Crustal permeability. Wiley, Chichester, UK, pp 137-154

Cann JR, McCaig AM, Yardley BWD (2016) Rapid generation of reaction permeability in the roots of black smoker systems. In: Crustal permeability. Wiley, Chichester, UK, pp 195-205

Connolly JAD, Podladchikov YY (2016) An analytical solution for solitary porosity waves: dynamic permeability and fluidization of nonlinear viscous and viscoplastic rock. In: Crustal permeability. Wiley, Chichester, UK, pp 285-306

Daigle H, Screaton EJ (2016) Evolution of permeability during sediment burial and subduction. In: Crustal permeability. Wiley, Chichester, UK, pp 104-121

Elkhoury JE, Brodsky EE, Agnew DC (2006) Seismic waves increase permeability. Nature 441:1135-1138

Ellsworth WL (2013) Injection-induced earthquakes. Science 341:142

Fan Y, Richard S, Bristol RS, Peters SE, et al (2016) DigitalCrust: a 4D system of material properties for transforming research on crustal fluid flow. In: Crustal permeability. Wiley, Chichester, UK, pp 6-12

Gleeson T, Ingebritsen SE (eds) (2016) Crustal permeability. Wiley, Chichester, UK

Häring MO, Schanz U, Ladner F, Dyer BC (2008) Characterisation of the Basel 1 enhanced geothermal system. Geothermics 37:469-495

Howald T, Person M, Campbell A, Lueth V, Hofstra A, Sweetkind D, Gable CW, Banerjee A, Luijendijk E, Crossey L, Karlstrom K, Kelley S, Phillips FM (2016) Evidence for long-timescale (>10 $0^{3}$ years) changes in hydrothermal activity induced by seismic events. In: Crustal permeability. Wiley, Chichester, UK, pp 260-274

Hsieh PA, Bredehoeft JD (1981) A reservoir analysis of the Denver earthquakes: a case of induced seismicity. J Geophys Res 86:903-920

Ingebritsen SE, Manning CE (1999) Geological implications of a permeability-depth curve for the continental crust. Geology 27: $1107-1110$

Ingebritsen SE, Manning CE (2010) Permeability of the continental crust: dynamic variations inferred from seismicity and metamorphism. Geofluids 10:193-205

Kitagawa Y, Fujimoro K, Koizumi N (2007) Temporal change in permeability of the Nojima fault zone by repeated water injection experiments. Tectonophys 443:183-192

Luijendijk E, Gleeson T (2016) How well can we predict permeability in sedimentary basins? Deriving and evaluating porosity-permeability relations for noncemented sand and clay mixtures. In: Crustal permeability. Wiley, Chichester, UK, pp 89-103

Lowell RP, Van Cappellen P, Germanovich LN (1993) Silica precipitation in fractures and the evolution of permeability in hydrothermal upflow zones. Science 260:192-194

Lucier A, Zoback MD (2008) Assessing the economic feasibility of regional deep saline aquifer $\mathrm{CO}_{2}$ injection and storage: a geomechanics-based workflow applied to the rose run sandstone in eastern Ohio, USA. Int J Greenhouse Gas Control 2:230-247

Manga M, Beresnev I, Brodsky EE, Elkhoury JE, Elsworth D, Ingebritsen SE, Mays DC, Wang C-Y (2012) Changes in permeability caused by transient stresses: field observations, experiments, and mechanisms. Rev Geophys 50. https://doi.org/10.1029/ 2011RG000382

Micklethwaite S, Ford A, Witt W, Sheldon HA (2016) Transient permeability in fault stepovers and rapid rates of orogenic gold deposition. In: Crustal permeability. Wiley, Chichester, UK, pp 249-259
Miller SA (2016) Modeling enhanced geothermal systems and the essential nature of large-scale changes in permeability at the onset of slip. In: Crustal permeability. Wiley, Chichester, UK, pp 353-362

Nazareth JJ, Hauksson E (2004) The seismogenic thickness of the southern California crust. Bull Seismol Soc Am 94:940-960

Neglia S (1979) Migration of fluids in sedimentary basins. Am Assoc Petrol Geol Bull 63:573-597

Okada T, Matsuzawa T, Umino N, et al (2016) Hypocenter migration and crustal seismic velocity distribution observed for inland earthquake swarms induced by the 2011 Tohoku-Oki earthquake in NE Japan: implications for crustal fluid distribution and crustal permeability. In: Crustal permeability. Wiley, Chichester, UK, pp 307-323

Preisig G, Eberhart E, Gischig V, Roche V, van der Baan M, Valley B, Kaiser PK, Duff D, Lowther R (2016) Development of connected permeability in massive crystalline rocks through hydraulic fracture and shearing accompanying fluid injections. In: Crustal permeability. Wiley, Chichester, UK, pp 337-352

Ranjram M, Gleeson T, Luijendijk E (2016) Is the permeability of crystalline rock in the shallow crust related to depth, lithology, or crustal setting? In: Crustal permeability. Wiley, Chichester, UK, pp 125-136

Rojstaczer SA, Wolf S, Michel R (1995) Permeability enhancement in the shallow crust as a cause of earthquake-induced hydrological changes. Nature 373:237-239

Saffer DM (2016) The permeability of active subduction plate boundary faults. In: Crustal permeability. Wiley, Chichester, UK, pp 209-227

Sanford WE, Konikow LF (1989) Simulation of calcite dissolution and porosity changes in salt water mixing zones in coastal aquifers. Water Resour Res 25:655-667

Sharp JM Jr, Domenico PA (1976) Energy transport in thick sequences of compacting sediment. Geol Soc Am Bull 87:390-400

Tanaka A, Ishikawa Y (2005) Crustal thermal regime inferred from magnetic anomaly data and its relationship to seismogenic layer thickness: the Japanese islands case study. Phys Earth Planet Int 152: $257-266$

Taron J, Ingebritsen SE, Hickman S, Williams CF (2016) Dynamics of permeability evolution in simulated geothermal reservoirs. In: Crustal permeability. Wiley, Chichester, UK, pp 363-372

University of Victoria (2017) Crustal Permeability Data Portal. University of Victoria, British Colombia. http://crustalpermeability. weebly.com/. Accessed August 2017

Wang C-Y, Manga M (2010) Earthquakes and water. Lecture Notes in Earth Sciences, 114, Springer, Berlin

Watanabe N, Numakura T, Sakaguchi K, Saishu H, Okamoto A, Ingebritsen SE, Tsuchiya N (2017) Potentially exploitable geothermal reservoirs may form in the ductile crust. Nat Geosci 10:140 144. https://doi.org/10.1038/NGEO2879

Weingarten M, Ge S, Godt JW, Bekins BA, Rubinstein JL (2015) Highrate injection is associated with the increase in US midcontinent seismicity. Science 348:1336-1340

Weis P (2016) The dynamic interplay between saline fluid flow and rock permeability in magmatic-hydrothermal systems. In: Crustal permeability. Wiley, Chichester, UK, pp 373-392

Wilkinson BH, McElroy BJ, Kesler SE, Peters SE, Rothman ED (2009) Global geologic maps are tectonic speedometers: rates of rock cycling from area-age frequencies. Geol Soc Am Bull 121:760-779

Yardley BWD (2016) The permeability of crustal rocks through metamorphic cycles: an overview. In: Crustal permeability. Wiley, Chichester, UK, pp 277-284 